\title{
Pengaruh Permainan Acak Geometri Terhadap Perkembangan Kecerdasan Logika-Matematika Anak
}

\author{
Ruliana Fajriati \\ Program Studi Magister PIAUD UIN Sunan Kalijaga Yogyakarta \\ Jalan Marsda Adisucipto, Papringan, Caturtunggal, Kec. Depok, Kabupaten Sleman, \\ Daerah Istimewa Yogyakarta, 55281 \\ Email: rulianafajriati@gmail.com
}

Naskah diterima: 27 November 2019, direvisi: 21 Maret 2020, diterbitkan: 31 Maret 2020

\begin{abstract}
Abstrak
Berdasarkan hasil pengamatan di lapangan terhadap perkembangan kecerdasan logikamatematika pada anak didik belum berkembang dengan optimal sehingga perlu dilakukan penerapan permainan acak geometri. Penelitian ini bertujuan untuk mengetahui pengaruh permainan acak geometri terhadap perkembangan kecerdasan logika-matematika pada anak di TK Nasyithatun Nisa Teluk Kiambang Kecamatan Tempuling Kabupaten Indragiri Hilir. Sampel yang digunakan dalam penelitian ini 13 orang anak didik yang terdiri dari satu kelas. Adapun teknik pengumpulan data yang digunakan yaitu tes, observasi dan dokumentasi. Teknik analisis data menggunakan uji Prasyarat dan uji Hipotesis dengan menggunakan program SPSS 17. Hipotesis penelitian adalah kegiatan penggunaan permainan acak geometri mempunyai pengaruh terhadap perkembangan kecerdasan logika-matematika pada anak kelompok B di TK Nasyithatun Nisa. Hal ini dapat diketahui dari hasil analisa data pada perbandingan pretest dan posttest yang diperoleh $t_{\text {hitung }}=50,229$ dan Sig. $(2$-tailed $)=0.000$. karena Sig. $(2$-tailed $)=0.000<0,05$ maka dapat disimpulkan bahwa terdapat pengaruh yang signifikan setelah menggunakan permainan acak geometri dalam pembelajaran. Jadi artinya Ho ditolak dan Ha diterima yang berarti dalam penelitian ini terdapat pengaruh permainan acak geometri sebelum dan sesudah perlakuan. Pengaruh permainan acak geometri terhadap perkembangan kecerdasan logika-matematika pada anak di TK Nasyithatun Nisa sebesar 82,005\%.
\end{abstract}

Kata kunci: Perkembangan Kecerdasan Logika-Matematika, Permainan Acak Geometri 


\begin{abstract}
Based on the results of observations in the field on the development of mathematical logical intelligence in students has not developed optimally so it is necessary to apply the geometry random game media. This study aims to determine the effect of random geometry on the development of mathematical-logic intelligence in children at Nasyithatun Nisa Kindergarten, Teluk Kiambang, Tempuling District, Indragiri Hilir Regency. The sample used in this study was 13 students consisting of one class. The data collection techniques used are test, observation and documentation. The data analysis technique used the Prerequisite test and Hypothesis test using the SPSS 17. The research bypothesis was that the activity of using geometric random games had an influence on the development of mathematical-logic intelligence in group B children at Nasyithatun Nisa Kindergarten. This can be seen from the results of data analysis on the comparison of the pretest and posttest classes obtained by tcount $=50,229$ and Sig. (2-tailed) $=0,000$. because of Sig. (2tailed $)=0,000<0,05$, it can be concluded that there is a significant effect after using geometric random play in learning. So that means Ho is rejected and Ha is accepted, which means that in this study there is the influence of random geometry games before and after treatment. The effect of random geometry on the development of logic-mathematical intelligence in children at Nasyithatun Nisa Kindergarten was $82,005 \%$.
\end{abstract}

Keywords: Development of Logic-Mathematical Intelligence, Random Geometry Games

\title{
Pendahuluan
}

Semua anak pada dasarnya adalah cerdas. Melalui kecerdasan yang dimilikinya setiap anak mampu mengeksplorasi dunianya dan memecahkan masalah yang dihadapinya. Berbagai kecerdasan yang dimiliki oleh masing-masing anak dapat menjadi modal dalam belajar.

Seperti yang dikutip oleh Thomas Armstrong, Howard Gardner menantang kepercayaan yang diyakini umum ini. Ia mengatakan bahwa budaya kita telah mendefinisikan kecerdasan terlalu sempit, ia menguslkan dalam bukunya Frames of Mind bahwa setidaknya terdapat tujuh kecerdasan dasar dan ia telah menambahkan menjadi delapan (Thomas Armstrong, 2013:5).

Guru PAUD hendaknya dapat memahami dan mengetahui pentingnya kecerdasan logika-matematika. Kecerdasan logika-matematika adalah kemampuan mengolah angka dan atau kemahiran menggunakan logika. Anak-anak yang mempunyai kelebihan dalam kecerdasan logika-matematika tertarik memanipulasi lingkungan serta cenderung suka menerapkan strategi coba ralat. Mereka suka menduga-duga sesuatu. Anak-anak yang memiliki kecerdasan ini terus menerus bertanya dan memiliki rasa ingin tahu yang besar tentang peristiwa di sekitarnya (Rita Kurnia, 2009:117). 
Proses pembelajaran anak usia dini, khususnya di Taman Kanak-kanak menjadi permasalahan karena dalam pola pembelajarannya cenderung menekankan pada akademik. Selain itu kurangnya media pembelajaran menjadi hambatan dalam proses pembelajaran untuk mengembangkan kecerdasan pada anak.

Dari pernyataan di atas, kita mengetahui bahwa bermain merupakan sarana anak memperoleh informasi dan mengembangkan potensi kecerdasannya. Guru dan orang tua hendaknya kreatif dalam mengoptimalkan alat permainan yang edukatif agar dapat mengembangkan potensi kecerdasan anak.

Untuk itu peneliti melakukan penelitian mengenai pengaruh permainan acak geometri terhadap perkembangan kecerdasan logika-matematika anak. Tujuan penelitian ini yaitu untuk mengetahui ada atau tidaknya pengaruh permainan acak geometri terhadap perkembangan kecerdasan logika-matematika anak.

\section{Metodologi}

Penelitian ini menggunakan metode eksperimen dengan One Group Pretest-Posttest Design yaitu terdapat satu kelompok diberi pretest sebelum diberi treatment/perlakuan dan selanjutnya diobservasi hasilnya.

Keterangan :

$$
\mathrm{O}_{1} \quad \mathrm{X} \quad \mathrm{O}_{2}
$$

$$
\begin{array}{ll}
\mathrm{O}_{1} & : \text { nilai pretest } \\
\mathrm{O}_{2} & : \text { nilai posttest } \\
\mathrm{X} & : \text { perlakuan (treatment) } \\
\mathrm{O}_{1}-\mathrm{O}_{2} & : \text { pengaruh perlakuan (treatment) }
\end{array}
$$

Penelitian ini dilaksanakan di TK Nasyithatun Nisa Jalan Kusuma RT. 001 RW.001 Desa Teluk Kiambang Kecamatan Tempuling Kabupaten Indragiri Hilir. Penelitian ini dilaksanakan pada bulan Agustus sampai bulan September 2018.

Subjek dalam penelitian ini adalah anak dan guru di TK Nasyithatun Nisa Teluk Kiambang Kecamatan Tempuling Kabupaten Indragiri Hilir, berjumlah 13 anak dan 1 orang guru kelas kelompok B. Sedangkan yang menjadi objek penelitian ini adalah pengaruh permainan acak geometri terhadap perkembangan kecerdasan logika- 
matematika anak kelompok B TK Nasyithatun Nisa Teluk Kiambang Kecamatan Tempuling Kabupaten Indragiri Hilir.

Penelitian ini terdiri dari dua variabel yaitu permainan acak geometri (variabel X) dan perkembangan kecerdasan logika-matematika (variabel Y).

Populasi adalah wilayah generalisasi yang terdiri dari objek atau subjek yang mempunyai kualitas dan karakteristik tertentu yang ditetapkan oleh penelitian untuk dipelajari dan kemudian ditarik kesimpulannya. Sampel adalah bagian dari jumlah dan karakteristik yang dimiliki oleh populasi tersebut.

Populasi dalam penelitian ini adalah anak-anak kelompok B TK Nasyithatun Nisa Teluk Kiambang Kecamatan Tempuling Kabupaten Indragiri Hilir, terdiri dari satu kelas yaitu berjumlah 13 anak. Karena populasinya sedikit, sehingga peneliti tidak mengambil sampel (Total Sampling).

Adapun data yang diperlukan pada penelitian ini adalah data primer, yaitu data yang dihimpun langsung oleh peneliti. Instrument yang digunakan dalam penelitian ini yaitu tes dengan memberikan Lembar Kerja Anak (LKA) kepada anak.

Teknik pengumpulan data yang digunakan dalam penelitian ini yaitu tes, observasi, dan dokumentasi. Tes yang digunakan peneliti berupa pemberian lembar kerja (LKA) anak dimana anak mencocokkan dan mengelompokkan bentuk geometri dengan benda-benda dalam kehidupan sehari-hari, yang dilaksanakan saat pretest dan posttest.

Adapun hal-hal yang akan di observasi adalah tentang bagaimanakah pengaruh permainan acak geometri terhadap perkembangan logika-matematika anak serta bagaimana peran guru dalam melaksanakan dan mengembangkan logika-matematika anak melalui permainan acak geometri. Selain itu observasi juga digunakan untuk menilai kegiatan anak dan hasil tes anak.

Dokumentasi digunakan untuk memperoleh data tentang keadaan sekolah, guru, anak, serta sarana dan prasarana di TK Nasyithatun Nisa Teluk Kiambang Kecamatan Tempuling.

Teknik analisis data yang digunakan pada penelitian ini adalah teknik analisis ujit. Untuk melihat apakah ada pengaruh permainan acak geometri terhadap perkembangan kecerdasan logika-maematika anak sebelum dan sesudah diberi 
perlakuan. Adapun proses dalam analisis data ini menggunakan rumus uji-t digunakan untuk menguji signifikan perbedaan mean.

\section{Hasil dan Diskusi}

Untuk mengetahui seberapa besar efektif pengaruh kegiatan permainan acak geometri terhadap perkembangan kecerdasan logika matematika anak di TK Nasyithatun Nisa Teluk Kiambang Kecamatan Tempuling Kabupaten Indragiri Hilir.

$$
\begin{aligned}
& \mathrm{G}=\frac{\text { skor Akhir }(\text { Posttes)-Skor Awal (Pretest) }}{\text { Skor Maksimal-Skor Awal (pretest) }} \times 100 \% \\
& \mathrm{G}=\frac{502-183}{572-183} \times 100 \% \\
& \mathrm{G}=\frac{319}{389} \times 100 \% \\
& \mathrm{G}=82,005 \%
\end{aligned}
$$

Keterangan:

$$
\begin{array}{ll}
\text { G } & =\text { Selisih antara nilai pretest dan posttest } \\
\text { Posttest } & =\text { Nilai setelah dilakukan esprimen } \\
\text { Pretest } & =\text { Nilai sebelum eksprimen } \\
100 \% & =\text { Angka tetap }
\end{array}
$$

Berdasarkan hasil penelitian dapat dilihat bahwa pengaruh perlakuan yang diberikan dalam kegiatan permainan acak geometri terhadap perkembangan kecerdasan logika matematika anak di TK Nasyithatun Nisa Teluk Kiambang Kecamatan Tempuling Kabupaten Indragiri Hilir adalah sebesar 82,005\%. Terdapat 3 kategori perolehan skor gain ternormalisasi yaitu:

Tabel 1. Kategori Gain Ternormalisasi

\begin{tabular}{cc}
\hline \multicolumn{2}{c}{ Gain Ternormalisasi } \\
\hline Gain Ternormalisasi & Kriteria Penilaian \\
$\mathrm{G}<30$ & Rendah \\
$30 \%<\mathrm{G}<70 \%$ & Sedang \\
$\mathrm{G}>70 \%$ & Tinggi \\
\hline
\end{tabular}


Merujuk pada hasil penggunaan rumus $G$ di atas, maka dapat di lihat kategori peningkatan sebesar $82,005 \%$ yaitu berada pada kategori Tinggi $<70 \%$.

Permainan acak geometri dapat mendorong anak untuk belajar dan mengetahui bentuk-bentuk geometri dengan mengklasifikasikan, membandingkan, menyusun, serta mencocokkan bentuk geometri dengan benda-benda dikehidupan sehari-hari. Dengan demikian, anak tidak merasa bosan dalam belajar karena adanya permainan yang bervariasi. Sehingga orang tua dan guru akan lebih udah menstimulasi dan mengembangkan potensi kecerdasan logika-matematika pada anak.

Berdasarkan hasil penelitian maka dapat diketahui bahwa perkembangan kecerdasan logika matematika anak dalam kegiatan permainan acak geometri sebelum adanya perlakuan diperoleh data anak yang berada pada kategori DN (Di atas Normal) sebanyak 0 orang anak dengan persentase $0 \%$, anak yang pada kategori $\mathrm{N}$ (Normal) sebanyak 0 orang anak dengan persentase $0 \%$, anak yang berada pada kategori $\mathrm{KN}$ (Kurang Normal) sebanyak 11 orang anak dengan persentase 84,6\%, anak dengan kategori SKN (Sangat Kurang Normal) sebanyak 2 anak dengan persentase 15,4\%.

Berdasarkan data di atas, perkembangan kecerdasan logika-matematika pada anak di TK Nasyithatun Nisa Teluk Kiambang Kecamatan Tempuling Kabupaten Indragiri Hilir masih rendah. Hal tersebut terlihat ketika peneliti melakukan pengamatan secara langsung kepada anak dimana anak masih belum bisa melakukan berbagai eksperimen, anak belum mampu memahami sebab-akibat, anak belum mampu melakukan kegiatan bermain yang berkaitan dengan berpikir logis seperti timbangmenimbang, dan anak belum mampu melakukan kegiatan bermain yang berkaitan dengan berpikir logis seperti permainan strategi.

Rendahnya kecerdasan logika-matematika pada anak di TK Nasyithatun Nisa Teluk Kiambang disebabkan oleh media pembelajaran yang kurang menarik sehingga anak kurang semangat dalam mengikuti pembelajaran. Berdasarkan hasil pretest yang telah dicapai, maka perlu peningkatan perkembangan kecerdasan logika-matematika anak dengan memberikan perlakuan/ treatment berupa pemberian permainan acak geometri.

Setelah pemberian treatment, anak memperlihatkan antusiasme ketika mengerjakan Lembar Kerja Anak (LKA). Bahkan anak sudah bisa memasangkan benda sesuai dengan pasangannya tanpa bantuan guru. Guru hanya mengarahkan anak diawal 
kegiatan saja. Setelah anak melaksanakan kegiatan permainan acak geometri, dilakukan evaluasi terhadap kecerdasan logika-matematika anak.

Berikut paparan data posttest, diketahui bahwa perkembangan kecerdasan logika matematika anak dalam kegiatan permainan acak geometri sesudah adanya perlakuan diperoleh data anak yang berada pada kategori DN sebanyak 13 dengan persentase $100 \%$, dan tidak terdapat anak didik yang berada pada kategori N, KN dan SKN atau $0 \%$.

Berdasarkan posttest yang dilakukan oleh peneliti dapat dilihat pada proses pembelajaran bahwa anak dapat berhitung di luar kepala dengan cepat sesuai dengan tingkat perkembangannya, anak dapat memberikan penjelasan secara logis atau rasional, anak bertanya mengapa, bagaimana, dan lain-lain, anak dapat melakukan berbagai eksperimen, anak dapat menyusun benda, orang, peristiwa, dan lain-lain sesuai dengan kategori, anak dapat menyusun benda, orang, peristiwa, dan lain-lain sesuai dengan hirarkinya, anak dapat memahami sebab-akibat, anak dapat melakukan kegiatan bermain yang berkaitan dengan berpikir logis seperti menghitung, anak dapat melakukan kegiatan bermain yang berkaitan dengan berpikir logis seperti timbang-menimbang, anak dapat melakukan kegiatan bermain yang berkaitan dengan berpikir logis seperti mengelompokkan, dan anak dapat melakukan kegiatan bermain yang berkaitan dengan berpikir logis seperti permainan strategi.

Pengujian hipotesis dalam penelitian ini menggunakan metode t-test untuk melihat perbedaan sebelum dan sesudah perlakuan serta untuk melihat seberapa besar pengaruh kegiatan permainan acak geometri terhadap perkembangan kecerdasan logika matematika anak.

Tabel 2. Paired Samples Test

\begin{tabular}{|c|c|c|c|c|c|c|c|c|}
\hline & \multicolumn{5}{|c|}{ Paired Differences } & \multirow[t]{2}{*}{$\mathrm{t}$} & \multirow[t]{2}{*}{ df } & \multirow[b]{2}{*}{$\begin{array}{l}\text { Std. Error } \\
\text { Mean }\end{array}$} \\
\hline & Mean & $\begin{array}{l}\text { Std. } \\
\text { Deviati }\end{array}$ & \multicolumn{2}{|c|}{ Std. Error } & $\begin{array}{l}95 \% \\
\text { Confidence } \\
\text { Interval of } \\
\text { the } \\
\text { Difference }\end{array}$ & & & \\
\hline & Lower & Upper & Lower & Upper & Lower & & & \\
\hline $\begin{array}{lr}\text { Pair } & \text { Pretest - } \\
1 & \text { Postes }\end{array}$ & $-24,53846$ & $\begin{array}{l}1,76 \\
141\end{array}$ & ,48853 & $\begin{array}{r}- \\
25,602 \\
87\end{array}$ & $-23,47405$ & $-50,229$ & 12 & ,000 \\
\hline
\end{tabular}


Sumber : Olahan Data, 2018

Berdasarkan hasil penelitian menunjukkan nilai uji statistik $\mathrm{t}_{\text {hitung }}$ sebesar -50,229 uji dua pihak berarti harga mutlak, sehingga nilai (-) tidak dipakai sehingga $t_{\text {hitung }}-50,229$. Karena nilai (Sig. 2-tailed) $=0,000<0,05$. Maka dapat peneliti simpulkan bahwa terdapat pengaruh permainan acak geometri terhadap perkembangan kecerdasan logika matematika anak signifikan setelah mendapat perlakuan dalam pembelajaran.

\section{Penutup}

Berdasarkan hasil penelitian yang dilaksankan di TK Nasyithatun Nisa Teluk Kiambang Kecamatan tempuling Kabupaten Indragiri Hilir diperoleh hasil analisa data pada perbandingan pretest dan posttest maka dapat disimpulkan bahwa terdapat pengaruh yang signifikan setelah menggunakan permainan acak geometri dalam pembelajaran. Artinya Ho ditolak dan Ha diterima yang berarti dalam penelitian ini terdapat pengaruh permainan acak geometri sebelum dan sesudah perlakuan.

\section{Daftar Pustaka}

Armstrong, Thomas. 2009. Multiple Intelligences in the Class Third Edition.Terjemah oleh Dyah Widya Prabaningrum. Jakarta: Indeks.

Hartati, Sofia. 2005. Perkembangan Anak Usia Dini. Jakarta: Depdiknas.

HP., Novianto. Kamus Lengkap bahasa Indonesia. Solo: Bringin 55.

Jakni. 2016. Metodologi Penelitian Eksperimen Bidang Pendidikan. Bandung: Alfabeta.

Jamaris, Martini. 2017.Pengukuran Kecerdasan Jamak. Bogor: Ghalia Indonesia.

Kadir. 2016. Statistika Terapan Edisi Kedua. Jakarta: RajaGrafindo Persada.

Khasanah, Ismatul dan Regelna Juniarti. 2015. Upaya Meningkatkean Kemampuan Mengenal Konsep Bilangan Melalui Media APE “Kubus Angka”" Pada Kelompok. A TK Tunas Rimba 1 Semarang Tahun 2013/2014. Educhild.Vol.4 No. 1. Di ambil dari: https://ejournal.unri.ac.id/index.php/JPSBE/article/view/2797 (25 Januari 2018).

Kurnia, Rita. 2009. Metodologi Pengembangan Matematika Anak Usia Dini. Pekanbaru: Cendikia Insani.

Kurnia, Rita. 2011. Bermain dan Permainan Anak Usia Dini. Pekanbaru: Cendikia Insani.

Mulyasa, H.E. 2016. Manajemen PAUD. Bandung: Remaja Rosdakarya. 
Nurlita. 2016. Meningkatkan Kemampuan Mengenal Bentuk Geometri Melalui Metode Proyek pada Anak Usia 5-6 Tahun di TK Mutiara Bunda Kecamatan Bangkinang Kota. Tugas Akhir. Fakultas Keguruan dan Ilmu Pendidikan Universitas Riau. Pekanbaru.

Pratiwi, Ellin Kartika. 2017. Pengarub Permainan Kereta Api Geometri Terhadap Kemampuan Geometri Anak Usia 4-5 Tabun di TK Pertiwi Selat Baru Kecamatan Bantan Kabupaten Bengkalis. Tugas Akhir. Fakultas Keguruan dan Ilmu Pendidikan Universitas Riau. Pekanbaru.

Riduwan. 2010. Skala Pengukuran Variabel-variabel Penelitian. Bandung: Alfabeta.

Sari, Desi Kumala. 2017. Penerapan Permainan Kartu Angka dalam Mengembangkan Logika Matematika Anak Usia 5-6 Tahun di TK Widya Bhakti Tanjung Senang Bandar Lampung. Tugas Akhir. Fakultas Tarbiyah dan Keguruan Universitas Islam Negeri Raden Intan Lampung. Lampung. http://repository.radenintan.ac.id/3252/1/Skripsi Full.pdf (25 Januari 2018)

Seefeldt, Carol dan Barbara A. Wasik. 2006. Early Education: Three, Four, and Five Year Olds Go to School. Terjemah oleh Pius Nasar. Jakarta: Indeks.

Sugiono. 2011. Metodologi Penelitian Pendidikan. Bandung: Alfabeta.

Sujiono, Yuliani Nurani dan Bambang Sujiono. 2010. Bermain Kreatif Berbasis Kecerdasan Jamak. Jakarta: Indeks.

Suyadi. 2014. Teori Pembelajaran Anak Usia Dini dalam Kajian Neurosains. Bandung: Remaja Rosdakarya.

Triharso, Agung. 2013. Permainan Kreatif \& Edukatif untuk Anak Usia Dini. Yogyakarta: ANDI.

Yaumi, Muhammad. 2012. Pembelajaran Berbasis Multiple Intelligences. Jakarta: Dian Rakyat. 